\title{
VAIZDINĖS GRIŽTAMOSIOS INFORMACIJOS POVEIKIS SKIRTINGO AMŽIAUS MOTERŲ PĖDOS LENKIMO IR TIESIMO JUDESIŲ KAITUMUI IR TIKSLUMUI
}

\author{
Vida Janina Česnaitienė, Albertas Skurvydas, Gediminas Mamkus, Vilma Juodžbalienė, \\ Dalia Mickevičienė, Edita Kavaliauskienė \\ Lietuvos kūno kultūros akademija, Kaunas, Lietuva
}

\begin{abstract}
Vida Janina Česnaitienė. Visuomenės sveikatos mokslų magistrẻ. Lietuvos kūno kultūros akademijos Tęstinių studijų centro metodininkẻ, Taikomosios fiziologijos ir kineziterapijos katedros asistenté, biologijos mokslų krypties doktorantė. Mokslinių tyrimų kryptis — senẻjimo itaka raumenų nuovargiui, judesių kaitumui ir stabilumui.
\end{abstract}

\section{SANTRAUKA}

Vaizdinè grǐztamoji informacija labai svarbi žmogaus judesiu valdymo procese, ypač izometriniu raumens susitraukimu metu. Vaizdinès grizžtamosios informacijos pagrindinis uždavinys judesiu valdymo procese yra kuo greičiau koreguoti jejgos dydị ir sumažinti judesio atlikimo laika, kaituma. Atliekant judesị be grižtamosios informacijos, pailgèja jo atlikimo laikas. Vyresniojo amžiaus tarpsniu tai gali sukelti eisenos sutrikimu ir padidinti griuvimo rizikq.

Šio tyrimo tikslas - nustatyti grižtamosios informacijos poveikị skirtingo amžiaus moteru pédos lenkimo ir tiesimo judesiu kaitumui ir tikslumui.

Buvo tiriama 30 sveiku skirtingo amžiaus moteru. 1 grupé — amžiaus vidurkis $70 \pm 5 \mathrm{~m} .(n=15), 2$ grupé 一 amžiaus vidurkis $25 \pm 5 \mathrm{~m}$. $(n=15)$. Tiriamosios buvo testuojamos žmogaus kaulu ir raumenu testavimo bei reabilitacijos aparatūra ,Biodex Medical System 3“. Jos atliko dešinès pédos izometrinị lenkimo ir tiesimo judesỉ suteikiant grižtamaja informacija ir be jos. Judesio tikslumas ir kaitumas buvo skaičiuojamas pagal R. A. Shmidt, T. D. Lee (1999) ir R. A. Magill (2007) pasiūlyta metodika.

Rezultatai parodè, kad visu tiriamuju maksimaliosios valingos jëgos momentas lenkiant péda yra statistiškai reikšmingai $(p<0,001)$ didesnis nei ja tiesiant. Jaunesniojo amžiaus tiriamuju maksimaliosios valingos jègos momentas lenkiant péda yra statistiškai reikšmingai $(p<0,05)$ didesnis nei vyresniojo amžiaus tiriamuju. Atliekant pédos lenkimo ir tiesimo judesius be grǐžtamosios informacijos, visu tiriamuju judesiu tikslumas sumažéjo statistiškai reikšmingai $(p<0,05)$. Vyresniojo amžiaus tiriamuju pèdos lenkimo ir tiesimo judesiu tikslumas statistiškai reikšmingai $(p<0,05)$ mažesnis nei jaunesniojo amžiaus tiriamuju.

Visu tiriamuju pédos lenkimo judesiu kaitumui grižtamoji informacija statistiškai reikšmingo poveikio neturejo. Atliekant pédos tiesimo judesius be grizztamosios informacijos, visu tiriamuju judesiu kaitumas statistiškai patikimai $(p<0,05)$ padidèjo. Lenkiant ir tiesiant péda jaunesnès tiriamosios statistiškai reikšmingai $(p<0,05)$ tikslesnès nei vyresniojo amžiaus.

Raktažodžiai: senèjimas, judesiu valdymas, tikslumas, kaitumas.

\section{IVADAS}

$\mathbf{J}$ udesio atlikimas - tai nuolatinis klaidų taisymas (Todorov, Jordan, 2002; Scott, 2004). Tam reikalingas grižtamasis ryšys. Vienas iš grižtamojo ryšio informacijos privalumų - sužinoma apie reikiamą pasiekti jègos dydic. Netekus šios informacijos, pablogeja judesio atlikimo tikslumas ir kaitumas (Todorov, 2004; Guigon et al., 2008), todè ji labai svarbi žmogaus judesiu valdymo procese, ypač izometrinių raumens susitraukimų metu. Grįžtamosios informacijos pa- grindinis uždavinys judesių valdymo procese yra kuo greičiau pakoreguoti judesị ir šitaip sumažinti judesio atlikimo laiką ir kaitumą (Hong, Newell, 2008).

Su amžiumi blogèja regimosios, vestibulinès sistemu, proprioreceptoriu, eksteroreceptorių veikla, centrinès nervų sistemos ir raumenų nervinè veikla (Ge'rome et al., 2003), dideja vyresniojo amžiaus žmonių judesių kinematinis kaitumas (Grabiner et al., 2001). Pailgejus judesio atliki- 
1 pav. Tyrimo atlikimo protokolas

Pastaba. MVJ - maksimaliosios valingos jègos momentas, GI - grižtamoji informacija, $\mathrm{P}$ - poilsis, $\mathrm{S}$ - izometrinis susitraukimas.

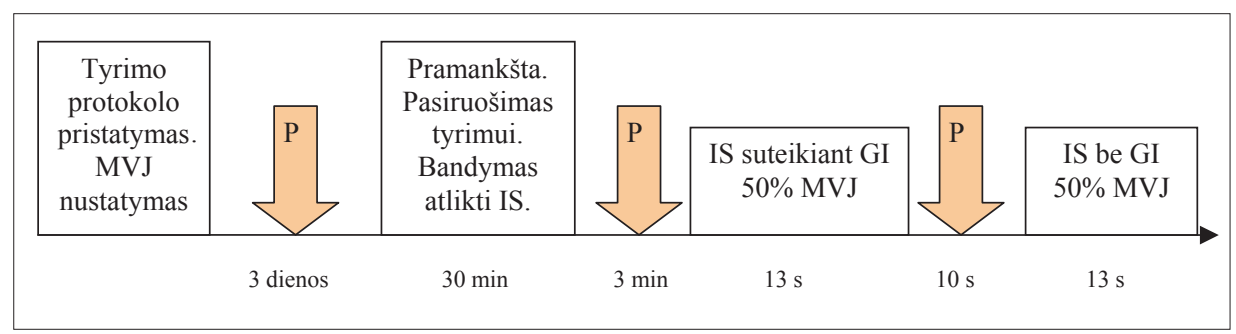

kaulų, raumenų testavimo ir reabilitacijos aparatūra Biodex Medical System 3. Buvo testuojama visu tiriamujų dešinè koja.

Maksimaliosios valingos jègos nustatymas. Maksimaliosios valingos jejgos momentą (MVJ) nustatėme izometriniu režimu, kai koja fiksuota per kelio sąnarị $20^{\circ} \mathrm{kampu}$, per čiurnos sąnari $-0^{\circ}$. Kampas tarp nugaros ir šlaunies $85^{\circ}$. Tiriamuju prašyta padidinti pėdos lenkimo jègą iki maksimumo ir išlaikyti 3 sekundes. Procedūra buvo atliekama 3 kartus, pailsint po 2 minutes. Didžiausias MVJ momento rezultatas buvo naudojamas tyrimui atlikti. Po 10 minučių pertraukos tiriant ta pačia metodika kaip ir lenkiant peddą buvo nustatomas tiriamuju MVJ momentas tiesiant pédą. Tiriamosios buvo raginamos didinti jègą ir dinamometro ekrane mate savo pasiektos jègos dydi. Tyrimo atlikimo protokolas pavaizduotas 1 paveiksle.

Pagal MVJ momento rezultatą buvo suskaičiuota kiekvienos tiriamosios 50\% MVJ reikšmè. Reikiamos procentinès jègos reikšmė, kurią reikèjo pasiekti ir išlaikyti, dinamometro ekrane buvo pažymèta horizontalia raudonos spalvos $1,5 \mathrm{~mm}$ storio linija. Ekrano įstrižainė $38 \mathrm{~cm}$. Atstumas nuo tiriamosios akiu iki ekrano $150 \mathrm{~cm}$. Tiriamosios atliko du $13 \mathrm{~s}$ trukmès izometrinius susitraukimus (IS): pirmą - teikiant grižtamają informaciją (GI), antrą - be GI. Atliekant antrą IS ekranas buvo uždengiamas baltos spalvos širma.

IS tikslumo ir kaitumo nustatymas. IS tikslumui įvertinti buvo skaičiuojamos absoliučios klaidos (AK) pagal R. A. Schmidt, T. D. Lee (1999) ir R. A. Magill (2006) pasiūlytą metodiką. Norėdami duomenis palyginti, skaičiavome kiekvienos tiriamosios AK dydi procentais nuo nustatyto MVJ momento:

$\mathrm{AK}(\%)=\mathrm{AK} \times 100 /(50 \% \mathrm{MVJ})$

IS kaitumui nustatyti skaičiavome variacijos koeficientą (VK) pagal formulę:

$$
V K=\frac{\sqrt{\sum\left(x_{i}-M\right)^{2} / n}}{M} \times 100 \%,
$$

čia $\mathrm{x}_{\mathrm{i}}$ - IS jègos momento dydis (N.m); M - IS vidurkis; $\mathrm{n}$ - bandymų skaičius. 
Grižtamosios informacijos ir amžiaus poveikis judesių kaitumui ir tikslumui buvo vertinamas naudojant neparametrinių kriterijų analizès metodą. Skirtumo reikšmingumą tarp rodiklių tikrinome Wilcoxon ir Mann-Whitney $U$ testais.

\section{REZULTATAI}

Visų tiriamujų MVJ momento rodikliai lenkiant pėdą yra statistiškai reikšmingai $(p<0,001)$ didesni nei tiesiant ( 2 pav.). Jaunesniojo amžiaus tiriamuju MVJ momentas lenkiant peddą yra statistiškai reikšmingai didesnis nei vyresniojo amžiaus tiriamuju (2 pav.).

Lenkiant ir tiesiant pèdą be GI, abiejų grupių tiriamuju judesių tikslumas sumažèjo statistiškai reikšmingai $(\mathrm{p}<0,05)$. Vyresniojo amžiaus tiriamosios statistiškai reikšmingai $(\mathrm{p}<0,05)$ daugiau klysta tiesdamos pedą $(\mathrm{AK}=8,3 \pm 3,3 \%)$ nei lenk-
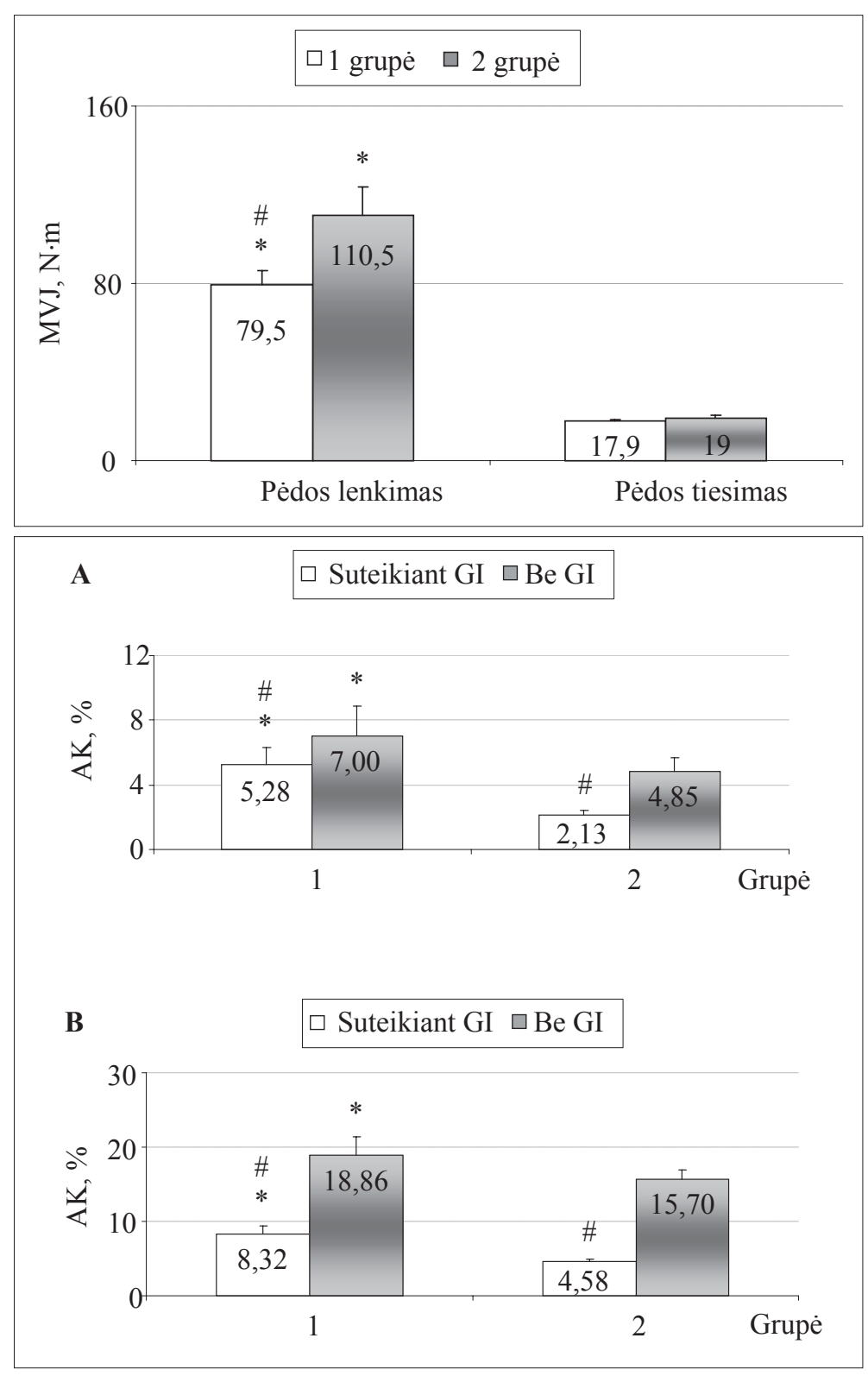

damos $(\mathrm{AK}=5,3 \pm 3,3 \%)$. Jaunesniojo amžiaus tiriamosios - tiesdamos pèdą $(\mathrm{AK}=4,6 \pm 1,2 \%)$ nei lenkdamos $(\mathrm{AK}=2,13 \pm 0,9 \%)$ ( 3 pav).

Abiejų grupių tiriamujų judesių kaitumas lenkiant peddą be GI statistiškai reikšmingai nepakito. Tiesiant pedą visų tiriamujų judesių kaitumas be GI statistiškai reikšmingai didesnis $(\mathrm{p}<0,05)$ nei suteikiant ją (3 pav.). Jaunesniojo amžiaus tiriamuju judesių kaitumas tiesiant pèdą (VK = $5,59 \pm 4,42 \%$ ) yra statistiškai reikšmingai didesnis $(\mathrm{p}<0,05)$ nei lenkiant $(\mathrm{VK}=1,67 \pm 1,1 \%)$. Vyresniojo amžiaus tiriamuju judesių kaitumas tiesiant pèdą (VK $=9,6 \pm 1,7 \%)$ taip pat yra statistiškai reikšmingai $(\mathrm{p}<0,05)$ didesnis nei lenkiant $(\mathrm{VK}=$ $2,51 \pm 1,6 \%)$.

Vyresniojo amžiaus tiriamujų pedos judesiu kaitumas lenkiant ir tiesiant pėdą yra statistiškai reikšmingai $(p<0,05)$ didesnis nei jaunesniojo amžiaus tiriamujų (4 pav.).

2 pav. Amžiaus poveikis maksimaliosios valingos jègos momentui lenkiant ir tiesiant pédą

Pastaba. \# - p $<0,05$, lyginant su 2 grupe; * - $\mathrm{p}<0,001$, lyginant su pèdos tiesimo rezultatais.

3 pav. Amžiaus ir grị̌tamosios informacijos poveikis izometrinių susitraukimų tikslumui
Pastaba. A — pédos lenkimo judesių tikslumas; B - pédos tiesimo judesių tikslumas. \# - $\mathrm{p}<0,05$, lyginant su pèdos judesiu tikslumu be GI; * - p $<0,05$, lyginant su 2 grupe. 
4 pav. Amžiaus ir grịžtamosios informacijos poveikis izometrinių susitraukimų kaitumui

Pastaba. A — pèdos lenkimo judesių kaitumas; B - pédos tiesimo judesių kaitumas. \# - $\mathrm{p}<0,05$, lyginant su pédos judesių kaitu$\mathrm{mu}$ be GI; * - p $<0,05$, lyginant su 2 grupe.

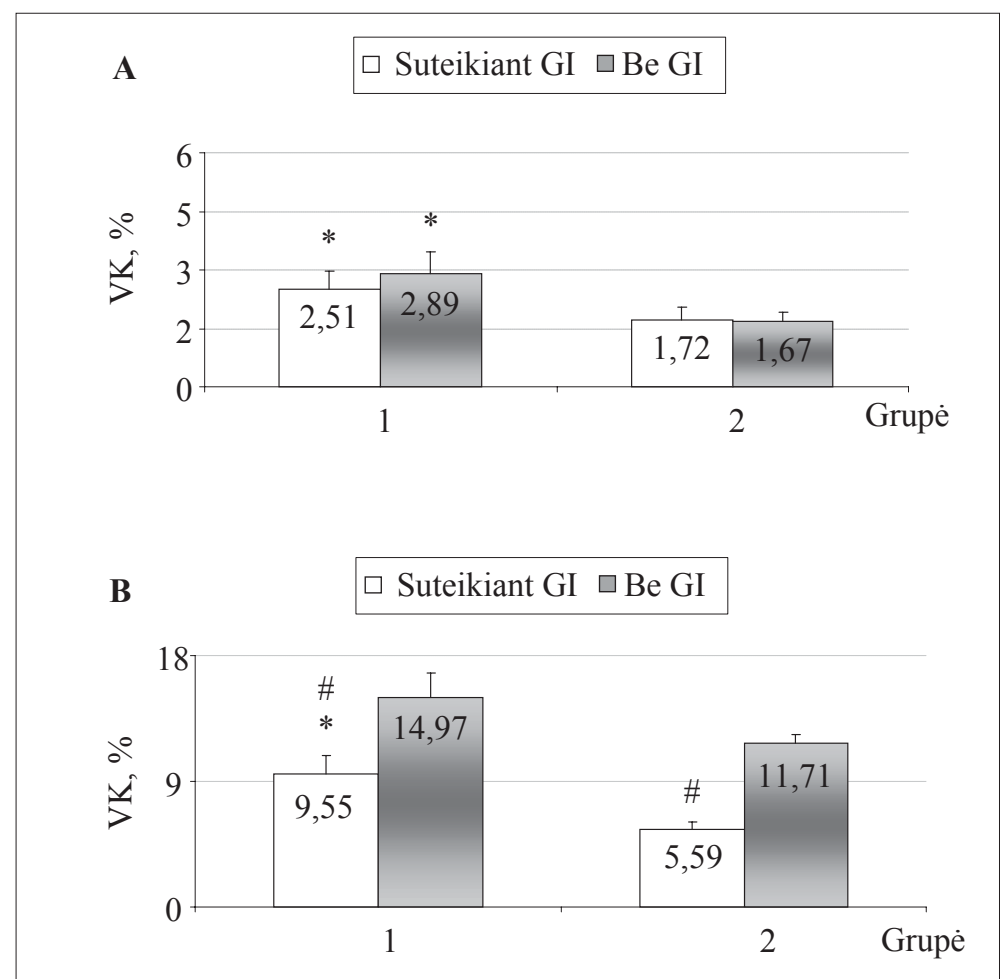

Jaunesniojo amžiaus tiriamosios statistiškai reikšmingai $(\mathrm{p}<0,05)$ mažiau klysta lenkdamos ir tiesdamos pẻdą, nei vyresnio amžiaus tiriamosios.

\section{REZULTATUQ APTARIMAS}

Tyrimo rezultatai parode, kad vyresniojo amžiaus tiriamujų MVJ momentas lenkiant pèdą yra statistiškai reikšmingai mažesnis nei jaunesniojo amžiaus tiriamujų. Pėdos tiesimo MVJ momentas abieju tirtu grupių statistiškai reikšmingai nesiskyrè. MVJ momento mažėjimą su amžiumi lemia griaučių raumenų masès mažejimas. Dèl amžiaus vykstančios raumenu atrofijos greičiausiai nyksta greitosios raumeninès skaidulos, todèl „lètujų“ raumenų susitraukimo jèga su amžiumi kinta lèčiau nei greitujų raumenų. E. A. Christou ir kt. (2004) nustatè, kad vyresniojo amžiaus žmonių judesių kaitumas didesnis nei jaunų, lyginant tų pačių raumenų izometrinius susitraukimus. Tyrejai teigia, kad viena iš judesiu kaitumo didejimo vyresniojo amžiaus tarpsniu priežasčių - motorinių vienetų kiekio mažèjimas. Tyrimo metu nustatėme, kad vyresniojo amžiaus tiriamuju judesio kaitumas lenkiant ir tiesiant pėdą yra statistiškai reikšmingai didesnis, o tikslumas mažesnis nei jaunesniojo amžiaus tiriamujų. Nuo seno vyrauja hipotezè: su amžiumi nervų sistemoje atsiranda vis daugiau trukdžių (Welford, 1984; Kail, 1997). Vyresniojo amžiaus žmonès regimają informaciją perteikia motorinei programai per ilgesnį laiką, ir tai padidina izometrinès jègos valdymo kaitumą. Pavyzdžiui, nesuteikiant grižtamosios regimosios informacijos, jègos kaitumas padidejja (Slifkin et al., 2000). Iš vyresniojo amžiaus žmonių atèmus galimybę matyti, sumažeja judesio atlikimo jèga (Vaillancourt, Newell, 2003). Manoma, kad jègos valdymo skirtumas vyresniojo amžiaus tarpsniu atsiranda dèl regimosios informacijos motorinio apdorojimo trukmès pailgèjimo (Vaillancourt et al., 2001), kuri parodo, kiek laiko reikia motorinès reakcijos klaidoms suvokti ir jas ištaisyti (Keele, Posner, 1968; Zelaznik et al., 1983). Žmonès veikia kaip paprastos grižtamosios informacijos valdymo sistemos, todèl pailgejus informacijos apdorojimo trukmei nukrypimas nuo taikinio būna didesnis (Craik, 1947 a, b). Visgi kiti mokslininkai nepastebejo, kad grižtamoji regimoji informacija kaip nors veiktų jègos valdymą (Christou, Carlton, 2001; Taylor et al., 2003), o kai kurie nustatè, kad tam tikromis eksperimento sąlygomis ji veikia neigiamai (Christou et al., 2004). Mūsų tyrimo rezultatai patvirtino hipotezę, kad dèl amžiaus atsirandantis regimosios informacijos motorinio apdorojimo trukmès skirtumas padidina jègos kaitumą (Vaillancourt et al., 2001). Atliekant pèdos lenkimo ir tiesimo judesius be GI, sumažèjo abiejų grupių tiriamujų judesių tikslumas, tačiau jaunesniojo amžiaus tiriamuju pèdos lenkimo ir tiesimo judesių tikslumas be GI pakito mažiau nei vyresniojo amžiaus tiriamujų. 
A. F. Hamilton ir kt. (2004) nustate, kad triukšmo lygis perduodant nervinès kontrolès signalus stambiuose raumenyse yra mažesnis nei smulkiuose. Sinerginèje raumenu grupèje pirmiausia aktyvuojami stambesni raumenys, ir taip garantuojamas mažesnis judesio atlikimo kaitumas ir didesnis tikslumas. Raumens dydžio ir judesių atlikimo kaitumo bei tikslumo ryši nagrinejjo keletas tyrèjų. E. A. Christou, L. G. Carlton (2002) nustate, kad kojų judesių kaitumas didesnis, o tikslumas mažesnis nei ranku judesių. A. F. Hamilton ir kt. (2004) nustatè, kad esant mažos jègos izometriniams raumens susitraukimams judesių kaitumas yra atvirkščiai proporcingas raumens dydžiui. Mūsų tyrimo rezultatai parodé, kad tiesiant pèdą judesiu kaitumas statistiškai reikšmingai didesnis nei lenkiant. Lenkiant pedą dalyvauja daugiau ir stambesni raumenys (trigalvis blauzdos raumuo, užpakalinis blauzdos raumuo, ilgieji lenkiamieji kojos pirštų raumenys, ilgasis lenkiamasis kojos nykščio raumuo, ilgasis šeivinis raumuo, trumpasis šeivinis raumuo) nei tiesiant pedą (priekinis blauzdos raumuo, ilgieji tiesiamieji kojos pirštu raumenys, ilgasis tiesiamasis kojos nykščio raumuo). Tai patvirtina A. F. Hamilton ir kt. (2004) teoriją, kad trukdys, perduodant nervinès kontrolès signalus, stambiuose raumenyse yra mažesni nei smulkiuose.

\section{IŠVADOS}

Vyresniojo amžiaus tiriamujų maksimaliosios valingos jègos momentas lenkiant pèdą statistiškai patikimai mažesnis nei jaunesniojo amžiaus tiriamujų. Tiesiant pėdą abiejų amžiaus grupių tiriamujų maksimaliosios valingos jègos momentai nesiskiria.

Statistiškai reikšmingai padidèja ir vyresniojo, ir jaunesniojo amžiaus tiriamuju judesio atlikimo kaitumas tiesiant pėdą be grižtamosios informacijos.

Jaunesniojo amžiaus tiriamujų pėdos lenkimo ir tiesimo judesių kaitumas mažesnis nei vyresniojo amžiaus tiriamujų, kai judesiai atliekami suteikiant grižtamają informaciją ir be jos.

Judesių tikslumas lenkiant ir tiesiant pèdą be grižžtamosios informacijos statistiškai reikšmingai sumažèjo visų tiriamujų. Lenkiant ir tiesiant pėdą jaunesniojo amžiaus tiriamosios statistiškai reikšmingai tikslesnès nei vyresnès.

\section{LITERATŪRA}

Baweja, H. S, Patel, B. K, Martinkewiz, J. D, Vu, J., Christou, E. A. (2009). Removal of visual feedback alters muscle activity and reduces force variability during constant isometric contractions. Experimental Brain Research, 197 (1), 35-47.

Bryden, M. P. (1977). Measuring handedness with questionnaires. Neuropsychologia, 15, 617-624.

Christou, E. A, Carlton, L. G. (2002). Age and contraction type influence motor output variability in rapid discrete tasks. Journal of Applied Physiology, 93, 489-498.

Christou, E. A., Carlton, L., G. (2001). Old adults exibit greater motor output variability than young adults only during rapid discrete isometric contractions. Journal of Gerontology: Biological Sciences, 56 A, 12, B 524-532.

Christou, E. A., Jakobi, J. M., Critchlow, A., Fleshner, M., Enoka, R. M. (2004). The 1- to 2-Hz oscillations in muscle force are exacerbated by stress, especially in older adults. Journal of Applied Physiology, 97, 225-235.

Craik, K. J. W. (1947 a). Theory of the human operator in control systems. Part 1. British Journal of Psychology, $38,56-61$.

Craik, K. J. W. (1947 b). Theory of the human operator in control systems. Part 2. British Journal of Psychology, $38,142-148$.

Ge'rome, C., Gauchard, A. B., Pierre Gangloff, A. B., Claude Jeandel, C., Philippe, P. (2003). Physical activity improves gaze and posture control in the elderly. Neuroscience Research, 45, 409- 417.

Grabiner, P. C, Biswas, S. T, Grabiner, M. D. (2001).
Age-related changes in spatial and temporal gait variables. Archives of Physical Medicine and Rehabilitation, $82,31-35$.

Guigon, E., Baraduc, P., Desmurget, M. (2008). Computational motor control: Feedback and accuracy. European Journal of Neuroscience, 27, 1003-1016.

Hamilton, A. F., Jones, K. A. E., Wolpert, D. M. (2004) The scaling of motor nuise with muscle strength and motor unit number in humans. Experimental Brain Research, 157, 417-430.

Hong, S. L., Newell, K. M. (2008). Visual information gain and the regulation of constant force levels. Experimental Brain Research, 189 (1),61-69.

Kail, R. (1997). The neural noise hypothesis: Evidence from processing speed in adults with multiple sclerosis. Aging, Neuropsychology and Cognition, 4, 157-165.

Keele, S. W., Posner, M. I. (1968). Processing of visual feedback in rapid movements. Journal of Experimental Psychology, 70, 387-403.

Kemoun, G., Thoumie, P., Boisson, D., Guieu, J. D. (2002). Ankle dorsiflexion delay can predict falls in the elderly. Journal of Rehabilitation Medicine: Official Journal of the UEMS European Board of Physical and Rehabilitation Medicine, 34 (6), 278-283.

Magill, R. A. (2007). Motor Learning and Control: Concepts and Applications. New York: McGraw-Hill.

Norris, J. A., Granata, K. P., Mitros, M. R., Byrne, E. M., Marsh, A. P. (2007). Effect of augmented plantarflexion power on preferred walking speed and economy in young 
and older adults. Gait Posture, 25 (4), 620-627.

Prodoehl, J., Vaillancourt, D. E. (2010). Effects of visual gain on force control at the elbow and ankle. Experimental Brain Research, 200 (1), 67-79.

Scott, S. H. (2004). Optimal feedback control and the neural basis of volitional motor control. Nature Reviews Neuroscience, 5, 532-546.

Shmidt, R. A., Lee, T. D. (1999). Motor Control and Learning: A Behavioral Emphasis. Human Kinetics. P. 544.

Slifkin, A. B., Vaillancourt, D. E., Newell, K. M. (2000). Intermittency in the control of continuous force production. Journal of Neurophysiology, 84, 1708-1718.

Taylor, A. M., Christou, E. A., Enoka, R. M. (2003). Multiple features of motor unit activity influence force fluctuations during isometric contractions. Journal of Neurophysiology, 90, 1350-1361.
Todorov, E. (2004). Optimality principles in sensorimotor control. Nature Neuroscience, 7 (9), 907-915.

Todorov, E., Jordan, M. I. (2002). Optimal feedback control as atheory of motor coordination. Nature Neuroscience, 5, 1226-1235.

Vaillancourt, D. E, Newell, K. M. (2003). Aging the time and frequency structure of force output variability. Journal of Applied Physiology, 94, 903-912.

Vaillancourt, D. E., Slifkin, A. B., Newell, K. M. (2001). Intermittency in the visual control of force in Parkinson's disease. Experimental Brain Research, 138, 118-127.

Welford, A. T. (1984). Between bodily changes and performance: Some possible reasons for slowing with age. Experimental Aging Research, 10, 73-88.

Zelaznik, H. N., Hawkins, B., Kisselburgh, L. (1983). Rapid visual feedback processing in single-aiming movements. Journal of Motor Behavior, 15, 217-236.

\title{
INFLUENCE OF VISUAL FEEDBACK ON ACCURACY AND VARIABILITY OF FOOT FLEXION AND EXTENSION OUTPUT OF WOMEN OF DIFFERENT AGE
}

\author{
Vida Janina Česnaitienė, Albertas Skurvydas, Gediminas Mamkus, Vilma Juodžbalienė, \\ Dalia Mickevičienė, Edita Kavaliauskienė \\ Lithuanian Academy of Physical Education, Kaunas, Lithuania
}

\begin{abstract}
Visual information is essential in human motor control, and especially in the continuous modulation of isometric force. The gain of visual feedback is, the amount of space used to represent change in force, has shown the affect in both the magnitude and time-dependent properties of variability in the force output.

The aim of this research was to establish the influence of visual feedback on the accuracy and variability of foot flexion and extension output of women of different age.

The studied subjects were healthy women free of neurological diseases: Group $1-15$ women (mean age $-70.0 \pm 5$ years,) and Group $2-15$ women (mean age $-25.0 \pm 5$ years). The subjects were tested applying the equipment for testing and rehabilitation of human bones and muscles (Biodex Medical System 3). We tested the right leg with visual feedback and without it. For the establishment of accuracy and variability of isometric contractions we calculated the absolute errors (Magill, 2007) and coefficient of variation.

The research results showed that maximum voluntary force of foot flexion was statistically significantly higher $(\mathrm{p}<0.001)$ than foot extension in both groups. The foot extension force was the same in both groups. Group 1 and Group 2 coefficients of variability of foot extension output with visual feedback were lower than without it $(\mathrm{p}<0.05)$. Group 1 made absolute errors of foot flexion and extension output less with visual feedback than without it $(\mathrm{p}<0.05)$.

We came to the conclusion that visual feedback improved the accuracy of foot flexion and extension, and the variability of foot extension was statistically significant in both groups of subjects. Older women demonstrated higher variability and made more mistakes in foot flexion and extension output than younger women.
\end{abstract}

Keywords: aging, motor control, accuracy, variability.

Gauta $2010 \mathrm{~m}$. kovo $15 \mathrm{~d}$.

Received on March 15, 2010

Priimta 2010 m. gegužès 31 d.

Accepted on May 31, 2010
Vida Janina Česnaitienè

Lietuvos kūno kultūros akademija

(Lithuanian Academy of Physical Education)

Sporto g. 6, LT-44221 Kaunas

Lietuva (Lithuania)

Tel +370 37302642

E-mail v.cesnaitiene@lkka.1t 